\title{
SHORT BASELINE TERRASAR-X PSI FOR MONITORING SUBSIDENCE OF HIGHWAYS AND RAILWAYS, CASE STUDY WITH CORNER REFLECTORS
}

\author{
Bing Yu, Guoxiang Liu, Hongguo Jia, Keren Dai, Rui Zhang, Tao Li, Xiaowen Wang, Deying Ma \\ Dept. of Remote Sensing and Geospatial Information Engineering, Southwest Jiaotong University, Chengdu, Sichuan, \\ 610031, China - rsbingyu@gmail.com
}

KEY WORDS: SAR, PSI, Short Baseline, Highways and Railways, Subsidence Monitoring, TerraSAR-X, Analysis

\begin{abstract}
:
Ground subsidence is one of the key factors causing damages to transportation facilities, e.g., transportation network (TN) consists of highways and railways. For better exploration of TN subsidence, we propose to use the high resolution TerraSAR-X (TSX) persistent scatterer interferometry (PSI) approach to extract regional scale (RS) subsidence related to the TN. The primary procedures involve interferometric pair selection, interferogram generation, persistent scatterer (PS) detection, PS networking, phase parameterization and subsidence estimation. Xiqing district of southwest Tianjin (China) is selected as the study area, in which multiple highways and one railway line are located. 15 TSX images collected over this area between March, 2009 and June, 2010 are utilized to extract subsidence by the TSX PSI approach. The subsidence rate (SR) map shows that remarkably uneven subsidence occurs along and around the TN, and the SR ranges between -69 and $-1.3 \mathrm{~mm} / \mathrm{yr}$. For validation purpose, the SR of the TN derived by PSI is compared with leveling data collected for the benchmarks deployed along the selected highways. The mean and root mean square error (RMSE) of discrepancies between two data sets are 0.1 and $\pm 3.2 \mathrm{~mm} / \mathrm{yr}$, respectively. The numerical analysis indicates that the high resolution TSX PSI is able to reveal comprehensive and detailed subsidence related to the TN with a millimeter level accuracy.
\end{abstract}

\section{INTRODUCTION}

It is well known that transportation plays a significant role in the development of national economy and the daily life of citizens $[1,2]$. As the primary transportation carriers, the modern transportation network (TN) consists of highways and railway lines takes on majority of traffic volumes. It is crucial to maintain sustainability and stability of such transportation infrastructures for keeping traffic safety [3]. Previous investigations indicate that ground subsidence caused by tectonic movements or anthropic activities such as overuse of groundwater is a major concern for land use planning, infrastructure sustainability evaluation and engineering construction [4]. The subsidence (especially the subsidence troughs) related to highways and railways is one of the key factors causing damages to the TN. This can impair sustainability and stability of the highways and railways, thus leading to decrease of traffic safety [3]. Therefore, monitoring the TN subsidence effectively and accurately in detail is of pressing necessity for preventing the relevant negative effects on transportations, especially in areas with intensive TN.

In the last few decades, the subsidence of highways and railways are generally measured by the conventional pointbased surveying (PBS) methods, e.g., leveling, wire-flex extensometer and global positioning system (GPS), etc. [4]. As a newly developed geodetic technique, synthetic aperture radar interferometry (InSAR) [5, 6] has exhibited great potential in mapping subsidence with advantages in spatial resolution and coverage as compared to the PBS methods. The InSAR technique has excellent ability to reveal spatial pattern of the subsidence in more detail. However, InSAR technique is inevitably affected by spatiotemporal decorrelation [7] and atmospheric delay [8], which significantly reduce the accuracy of InSAR measurements. To overcome such drawbacks, Ferretti et al. proposed the persistent scatterer interferometry (PSI) method in 2001 [9]. Since then, many PSI approaches were developed and tested with use of moderate spatiotemporal resolution SAR data such as ERS-1/2 and ENVISAT ASAR C band SAR images [10-12]. In spite of the differences in data processing strategies between different PSI approaches, this technique generally tracks deformations of the stable point-like targets, i.e. the so called persistent scatterers (PS) [9], with strategies to spatiotemporally analyze InSAR phase observations at the targets [9-12].

The recent X-band radar sensor onboard the German satellite TerraSAR-X (TSX) has capability of providing SAR images at very high spatial and temporal resolution of about $1-3 \mathrm{~m}$ and 11 days, respectively [13]. This extends the data availability for subsidence detection by PSI [13, 14]. For better exploration of TN subsidence, we propose to use the high resolution TSX PSI approach to extract regional scale (RS) subsidence of the TN. The utilized PSI approach includes strategies of interferometric pair selection, interferogram generation, persistent scatterer (PS) detection, PS networking and neighborhood differencing, phase parameterization and subsidence estimation. Xiqing district of southwest Tianjin (China) is selected as the study area, in which multiple highways and one railway line are located. 15 TSX images collected over this area between March 27, 2009 and June 2, 2010 are utilized to extract subsidence by the TSX PSI approach. To assess the accuracy of TN subsidence derived by the presented PSI approach, the subsidence of the TN measured by leveling are used as the reference data for comparative analysis.

\section{STUDY AREA AND DATA SOURCE}

\subsection{Study Area}

To study the applicability and potential of high resolution TSX PSI for inversion of TN subsidence, we select Xiqing district of Tianjin (China) as the study area. As shown in Fig. 1, Tianjin is located in the northeast part of China, bordering Beijing, Hebei province and the Bohai Bay to the northwest, the northeast and the east, respectively [15]. As one of the largest and most important industrial cities in north China, Tianjin suffers water shortage due to its natural geographic condition and semi-arid climate [15]. As a result, a large amount of groundwater (especially the deep phreatic water) has been exploited to meet the industrial and agricultural needs, thus leading to severe land subsidence in many areas of Tianjin [15]. 


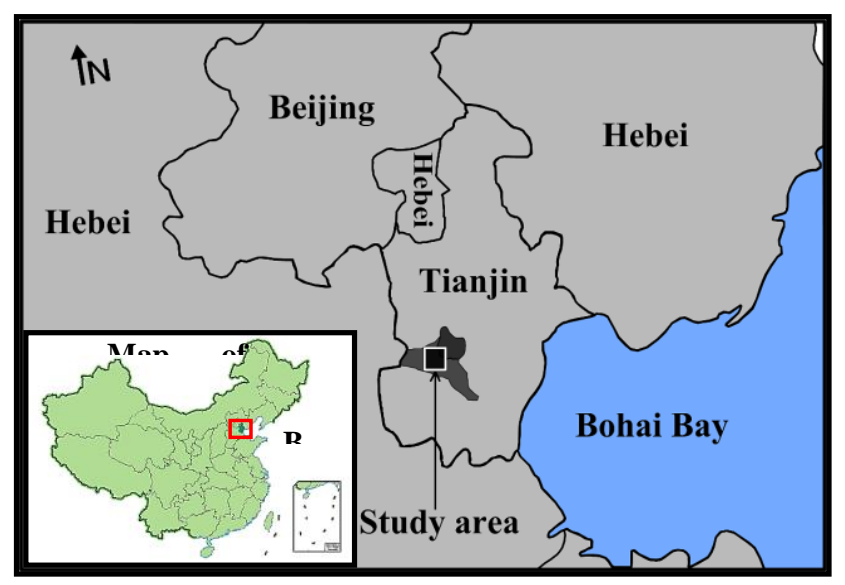

Fig. 1 Location map of the study area

As shown in Fig. 1, the study area (Xiqing) is located in the southwest of Tianjin, bordering Tianjin urban area to the northeast. Fig. 2 shows the averaged amplitude image of the study area. In recent years, many new industrial parks have been constructed and launched to daily producing in Xiqing. To meet the transportation needs from the increase of industrial production, some new highways were constructed in the last few years. As illustrated in Fig. 2, multiple highways and one railway line are located in the study area, forming a TN. In progress of industrial and agricultural production, massive groundwater in this area is being exploited to meet the increasing water needs for such producing activities. This is probable to result in remarkably uneven subsidence which can cause unevenness and straightness to the highway surface and the railway tracks $[1,2]$. Another circumstance should be taken into account is the dynamic and static loads from heavy vehicles (carrier trucks and trains). These additional burdens are to result in roadbed compression (i.e., subsidence), thus leading to distortion of the road surface and railway tracks. Therefore, it is necessary to monitor the subsidence along and around the highways and the railway in this area before it induces passible damages to the transportations.

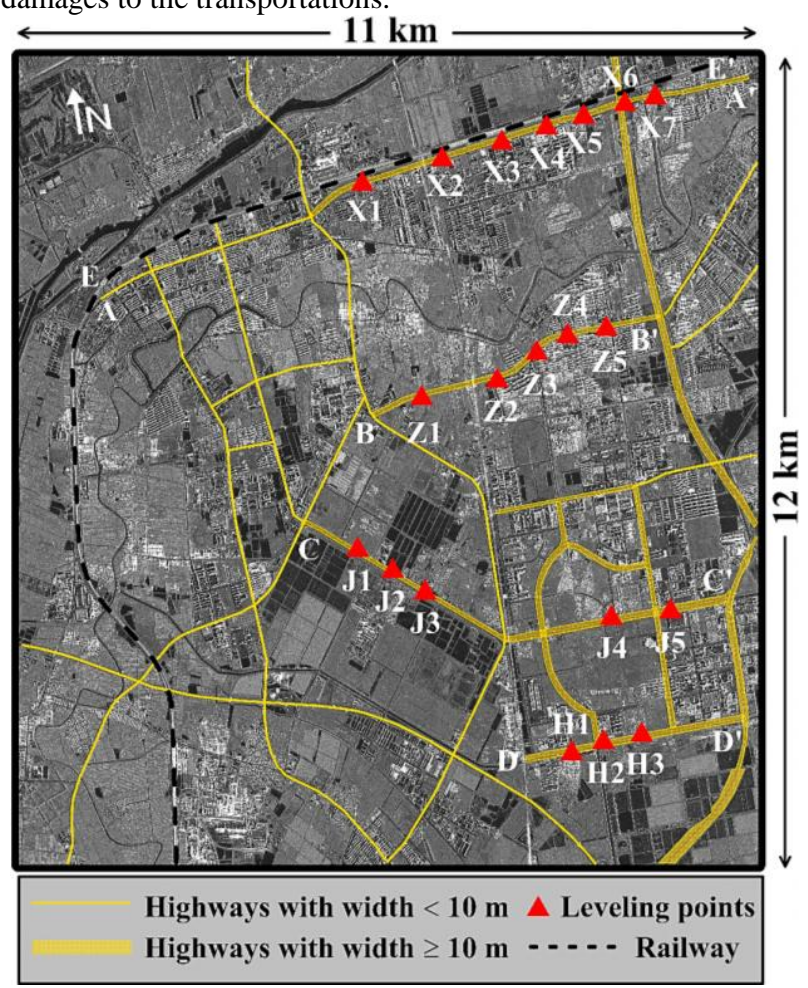

Fig. 2 Averaged amplitude image of the study area with annotation of highways, railway line and the LPs. Four highways and one railway line as annotated with $\mathrm{AA}^{\prime}, \mathrm{BB}^{\prime}, \mathrm{CC}^{\prime}$, DD' and EE' are selected for further analysis.

\subsection{Data Source}

To extract subsidence of the TN in the study area, 15 TSX SAR images acquired between March 27, 2009 and June 2, 2010 are used for PSI processing. All images are provided in single look complex (SLC) format with pixel spacing of $1.36 \mathrm{~m}$ in slant range (i.e., $2.07 \mathrm{~m}$ in ground range) and $1.90 \mathrm{~m}$ in azimuth. Fig. 2 shows the averaged TSX amplitude image of the study area of about $11 \times 12 \mathrm{~km} 2$. It is very easy to identify the roads, highways, buildings, fishponds and crop parcels from the amplitude image. As annotated in Fig. 2, 20 leveling points (LP) were deployed along 4 highways namely Xiqing road (AA'), Zhongbei road $\left(B^{\prime}\right)$, Jinjing road $\left(C^{\prime}\right)$ and South Haitai road (DD'). Three epochs of leveling campaigns were carried out on all the LPs. The acquired leveling data will be used to validate the subsidence derived by TSX PSI.

For interferometric processing, the image acquired on September 30 of 2009 is selected as the reference. All other images are co-registered and resampled into the same grid space as the reference image. In this study, we first generate 105 interferometric pairs (IP) by full combination of the 15 TSX images. The spatial (perpendicular) and temporal baselines (SB and TB) of the IPs range between 3.8 and $320 \mathrm{~m}, 11$ and 429 days, respectively. To recede spatial decorrelation in interferometric phases, only IPs with spatial baseline shorter than $150 \mathrm{~m}$ will be considered for processing. Finally, 53 interferograms are generated. Table 1 lists the general information (acquisition dates of master and slave images, SBs and TBs) of the interferograms. Subsequently, 53 differential interferograms are generated by the two-pass differential InSAR method with use of the DEM derived by the Shuttle Radar Topography Mission (SRTM) over the study area for removing topographic artifacts. 
Table 153 short baseline interferograms formed

\begin{tabular}{ccc|ccc|ccc}
\hline $\begin{array}{c}\text { Master/Slave } \\
\text { Dates in YMD }\end{array}$ & $\begin{array}{c}\text { SB } \\
(\mathrm{m})\end{array}$ & $\begin{array}{c}\text { TB } \\
\text { (days) }\end{array}$ & $\begin{array}{c}\text { Master/Slave } \\
\text { Dates in YMD }\end{array}$ & $\begin{array}{c}\text { SB } \\
(\mathrm{m})\end{array}$ & $\begin{array}{c}\text { TB } \\
\text { (days) }\end{array}$ & $\begin{array}{c}\text { Master/Slave } \\
\text { Dates in YMD }\end{array}$ & $\begin{array}{c}\text { SB } \\
(\mathrm{m})\end{array}$ & $\begin{array}{c}\text { TB } \\
(\text { days }\end{array}$ \\
\hline $090429 / 090510$ & 17 & 11 & $090510 / 100702$ & -109 & 418 & $090828 / 090930$ & -80 & 33 \\
$090429 / 090521$ & 51 & 22 & $090521 / 090704$ & -81 & 44 & $090828 / 100107$ & 77 & 132 \\
$090429 / 090704$ & -30 & 66 & $090521 / 090806$ & 73 & 77 & $090828 / 100220$ & -53 & 176 \\
$090429 / 090806$ & 125 & 99 & $090521 / 091102$ & 54 & 165 & $090828 / 100325$ & 111 & 209 \\
$090429 / 090828$ & -115 & 121 & $090521 / 091205$ & 62 & 198 & $090828 / 100702$ & 23 & 308 \\
$090429 / 091102$ & 106 & 187 & $090521 / 100107$ & -89 & 231 & $090930 / 100220$ & 26 & 143 \\
$090429 / 091205$ & 113 & 220 & $090521 / 100325$ & -55 & 308 & $090930 / 100702$ & 103 & 275 \\
$090429 / 100107$ & -37 & 253 & $090521 / 100702$ & -143 & 407 & $091102 / 091205$ & 7 & 33 \\
$090429 / 100325$ & -3 & 330 & $090704 / 090828$ & -84 & 55 & $091102 / 100107$ & -144 & 66 \\
$090429 / 100702$ & -91 & 429 & $090704 / 091102$ & 136 & 121 & $091102 / 100325$ & -110 & 143 \\
$090510 / 090521$ & 33 & 11 & $090704 / 091205$ & 143 & 154 & $091205 / 100107$ & -150 & 33 \\
$090510 / 090704$ & -48 & 55 & $090704 / 100107$ & -7 & 187 & $091205 / 100325$ & -117 & 110 \\
$090510 / 090806$ & 107 & 88 & $090704 / 100220$ & -138 & 231 & $100107 / 100220$ & -130 & 44 \\
$090510 / 090828$ & -132 & 110 & $090704 / 100325$ & 26 & 264 & $100107 / 100325$ & 33 & 77 \\
$090510 / 091102$ & 88 & 176 & $090704 / 100702$ & -61 & 363 & $100107 / 100702$ & -53 & 176 \\
$090510 / 091205$ & 95 & 209 & $090806 / 091102$ & -18 & 88 & $100220 / 100702$ & 77 & 132 \\
$090510 / 100107$ & -55 & 242 & $090806 / 091205$ & -11 & 121 & $100325 / 100702$ & -87 & 99 \\
$090510 / 100325$ & -21 & 319 & $090806 / 100325$ & -129 & 231 & & & \\
\hline
\end{tabular}

\section{PSI PROCEDURES}

\subsection{Detection of PSs}

Basically, we detect PSs by following the method proposed by Ferretti et al. [9]. A pixel is a NPS if it satisfies the following two empirical criteria

$$
\left\{\begin{array}{c}
D_{a m p}=\frac{\sigma_{a m p}}{\bar{a}} \leq 0.25 \\
\bar{a} \geq \bar{A}+\sigma_{A}
\end{array}\right.
$$

where $D_{\text {amp }}$ is the amplitude dispersion index (ADI) [9]; $\bar{a}$ and $\sigma_{a m p}$ are the mean and standard deviation (SD), respectively, of the amplitude time series at a pixel; $\bar{A}$ and $\sigma_{A}$ are the overall mean and SD of the amplitude values of all pixels in the mean amplitude image. The first criterion in (1) indicates that the pixels with smaller ADI are more temporally stable in radar backscattering than those with higher ADI, while the second criterion is introduced for that pixels with higher amplitude values tend to be more temporally coherent [12].

\subsection{PS Networking, Phase Parameterization and Subsidence Estimation}

After PS detection, all PSs are connected to form a Delaunay triangulation network (DTN) which is taken as the subsidence observation network (SON) [11]. Phase modeling is based on the concept of neighborhood differencing [11, 12] applied to each of the links in the SON.

Suppose there are $N$ differential interferograms, the phase value at two neighboring PSs (p and q) extracted from the $i$ th differential interferogram can be expressed by [12],

$\Phi_{i}^{p}=\frac{4 \pi \cdot B_{i}^{T}}{\lambda} \cdot v_{p} \cdot \cos \theta_{p}+\frac{4 \pi \cdot B_{i, p}^{\perp}}{\lambda \cdot R_{p} \cdot \sin \theta_{p}} \cdot \varepsilon_{p}+\widehat{\phi}_{i}^{p}$
$\Phi_{i}^{q}=\frac{4 \pi \cdot B_{i}^{T}}{\lambda} \cdot v_{q} \cdot \cos \theta_{q}+\frac{4 \pi \cdot B_{i, q}^{\perp}}{\lambda \cdot R_{q} \cdot \sin \theta_{q}} \cdot \varepsilon_{q}+\bar{\phi}_{i}^{q}$

where $\Phi_{i}^{*}$ is the wrapped phase at the PSs; $v$. and $\varepsilon$. are the subsidence rate (SR) and the elevation residual (ER, due to uncertainties in the SRTM DEM used) at the PSs, respectively; $B_{i}^{T}$ is the temporal baseline of the $i$ th interferogram; $B_{i, .}^{\perp}$ is the spatial (perpendicular) baseline at the PSs in the $i$ th interferogram; $\lambda$ is the radar wavelength $(3.1 \mathrm{~cm}$ for the TSX system); $R$. and $\theta$ are the sensor-to-target range and the radar incident angle at the PSs, respectively; $\hat{\varphi}_{i}^{\bullet}$ is the residual phase consisting of the nonlinear subsidence, atmospheric artifacts, orbit errors and decorrelation noise.

After the neighborhood differencing operation, the phase increment ( $\delta \Phi_{i}$ ) between the two adjacent PSs of each link can be derived using (2) and (3), and represented as a function of the SR increment $(\delta v)$, the ER increment $(\delta \varepsilon)$ and the residual phase increment $\left(\delta \hat{\phi}_{i}\right)$. $N$ differential equations can be obtained in this way using $N$ differential interferograms. For each link, $\delta v$ and $\delta \varepsilon$ can be estimated by maximize the following objective function [12],

$\left\{\begin{array}{l}\gamma=\max \left[\left|\frac{1}{N} \sum_{i=1}^{N}\left(\cos \omega_{i}+j \cdot \sin \omega_{i}\right)\right|\right] \\ \omega_{i}=\delta \Phi_{i}-\frac{4 \pi \cdot B_{i}^{T}}{\lambda} \cdot \delta v \cdot \cos \bar{\theta}-\frac{4 \pi \cdot \bar{B}_{i}^{\perp}}{\lambda \cdot \bar{R} \cdot \sin \bar{\theta}} \cdot \delta \varepsilon\end{array}\right.$

where $\bar{R}, \bar{\theta}$ and $\bar{B}_{i}^{\perp}$ are the mean sensor-to-target range, the mean radar incident angle, and the mean perpendicular baseline between two PSs, respectively; $\gamma$ is the model coherence (MC) of the link; $j=\sqrt{-1}$. It should be emphasized that $\delta v$ and $\delta \varepsilon$ can be derived by searching within a given solution space (e.g., -5 to $5 \mathrm{~mm} / \mathrm{yr}$ for $\delta v$, and -20 to $20 \mathrm{~m}$ for $\delta \varepsilon$ ) to maximize the MC. 
Once the SR and ER increments of all the links are estimated by (4), the SON can be treated by the weighted least squares (LS) adjustment to estimate the SRs and ERs of all the PSs. The square of the maximized MC value of each link is taken as the weight [12]. In addition, a LP with subsidence rate obtained by leveling measurements can be taken as a reference point for the LS adjustment.

\section{EXPERIMENTAL RESULTS AND ANALYSIS}

\subsection{Subsidence Rate Map and Interpretation}

The SR values at all PSs were extracted by the PSI approach presented in section 3 with the 53 differential interferograms. Then the SR map of the entire study area were generated and shown in Fig. 3. The map was composed of two layers. The color coded layer with a scale bar presents the magnitude and distribution of the estimated SRs, while the averaged amplitude image was taken as the base map layer. The color map reveals remarkably the uneven subsiding pattern with SR magnitude ranges between -69 and $-1.3 \mathrm{~mm} / \mathrm{yr}$, while the mean SR is -33.7 $\mathrm{mm} / \mathrm{yr}$. The results indicate that our study area is a predicably active zone for subsidence. Simultaneous inspections with Fig. 3 and Fig. 2 demonstrate that apparent subsidence was observed along and around the highways and railway line.

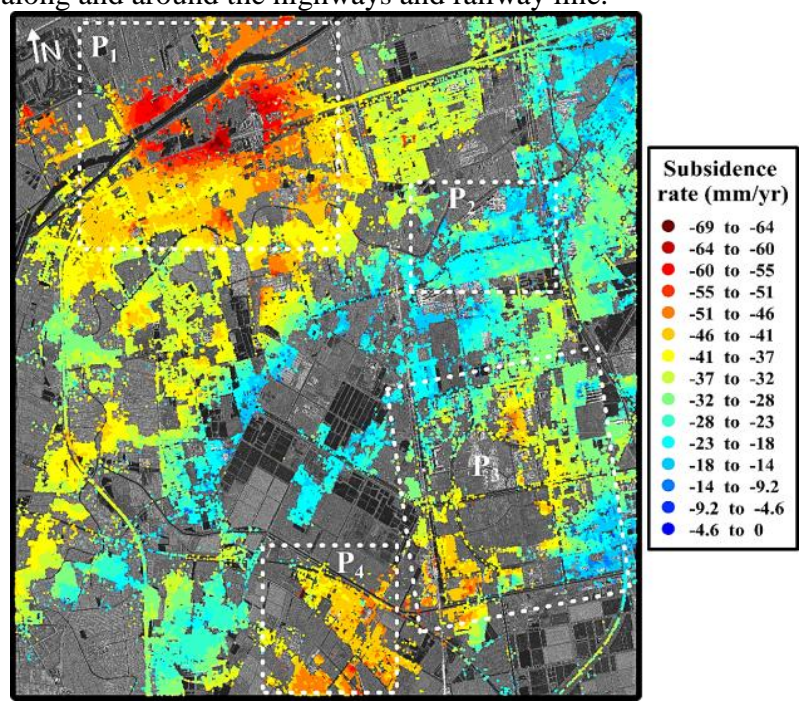

Fig. 3 SR map of the study area

Closer inspections with Fig. 3 demonstrate that the subsidence pattern of this study area is highly associated with local land use classification (LLUC). As examples, 4 typical areas (TA) are selected for further analysis. The 4 TAs are identified by the dashed rectangles namely $\mathrm{P}_{1}, \mathrm{P}_{2}, \mathrm{P}_{3}$ and $\mathrm{P}_{4}$, respectively, and the relevant optical images are shown in Fig. 4. For better presentation of SRs related to $\mathrm{P}_{1}, \mathrm{P}_{2}, \mathrm{P}_{3}$ and $\mathrm{P}_{4}$, the maximum, minimum and mean SRs of them are listed in Table 2. The highest $\mathrm{SR}$ is observed in $\mathrm{P}_{1}$ with maximum and mean magnitudes of -68.8 and $-50.6 \mathrm{~mm} / \mathrm{yr}$, respectively. $\mathrm{P}_{3}$ and $\mathrm{P}_{4}$ have relatively higher subsiding rate with mean values of -33.9 and $-44.8 \mathrm{~mm} / \mathrm{yr}$, respectively. $\mathrm{P}_{2}$ represents the relatively slower subsidence rate as compared with $\mathrm{P}_{1}, \mathrm{P}_{3}$ and $\mathrm{P}_{4}$. The maximum and mean $\mathrm{SRs}$ at $\mathrm{P}_{2}$ are -40.7 and $-26.2 \mathrm{~mm} / \mathrm{yr}$, respectively.

Table 2 Maximum, minimum and mean $\mathrm{SRs}(\mathrm{mm} / \mathrm{yr})$ at $\mathrm{P}_{1}, \mathrm{P}_{2}$, $\mathrm{P}_{3}$ and $\mathrm{P}_{4}$

Name Maximum SR Minimum SR Mean SR

\begin{tabular}{llll}
\hline $\mathrm{P}_{1}$ & -68.8 & -37.0 & -50.6 \\
$\mathrm{P}_{2}$ & -40.7 & -14.9 & -26.2 \\
$\mathrm{P}_{3}$ & -52.5 & -12.5 & -33.9 \\
$\mathrm{P}_{4}$ & -62.1 & -28.0 & -44.8 \\
\hline
\end{tabular}

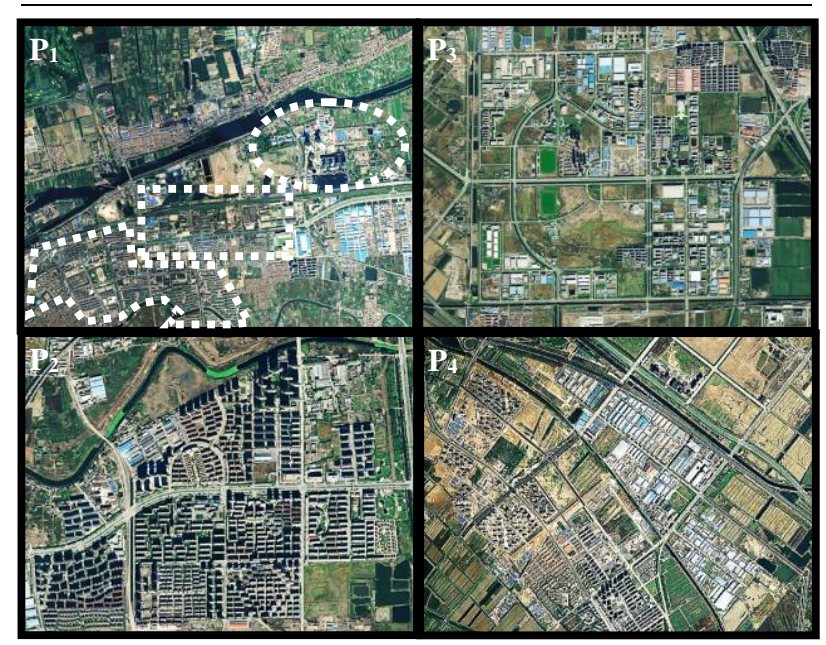

Fig. 4 Optical images related to P1, P2, P3 and P4, respectively According to our in-situ investigations, P1 is related to a thermal power plant (marked by the dashed oval), multiple industrial factories (marked by the dashed rectangle) and some residential quarters (marked by the dashed polygon), and P3 and P4 mainly correspond to the industrial parks, while P2 is related to the residential quarters. A justifiable factor accounts for the observed remarkable subsidence in these areas is groundwater extraction for productive and domestic water needs. The aquifer in this study area forms from the Neogene and such layer mainly belongs to the Neogene and quaternary sedimentary formation [4, 15]. Geologically, the aquifer is a thick clayey strata consists of grits and loose or semi-loose argillaceous sediments [15]. Excessive exploration of groundwater can lead to severe depression of water table, thus gives rise to run off of interstitial water. The consequence due to this process is aquifer compression accounts for the subsidence. Furthermore, the heterogeneous subsidence observed in this study area (see Fig. 3) owing to different pumping intensity of groundwater in different regions.

\subsection{Closer Inspections with Subsidence Related to the TN}

For better interpretation of the subsidence phenomena related to the TN (see Fig. 2), we select four highways and one railway line for further analysis. The selected highways and railway line are annotated in Fig. 2 by $\mathrm{AA}^{\prime}, \mathrm{BB}^{\prime}, \mathrm{CC}^{\prime}, \mathrm{DD}^{\prime}$ and $\mathrm{EE}^{\prime}$, respectively, namely Xiqing road, Zhongbei road, Jinjing road, South Haitai road and Jinpu railway, respectively. We first estimated the full resolution (original resolution of the SLC data, i.e., $2 \mathrm{~m}$ ) SRs along the highways and railway line with Kriging interpolation method. Then we extracted the SR profiles along the center line of each highway and the railway line. Fig. 5 (a)(e) has shown the SR profiles related to each highway and the railway line. Remarkably, Fig. 5 exhibits the uneven subsidence distributed along the studied transportation facilities. The maximum, minimum and mean SR values of each highway and the railway line are listed in table 3. Obviously, Jinpu railway and Xiqing highway have relatively higher SR than other highways. 


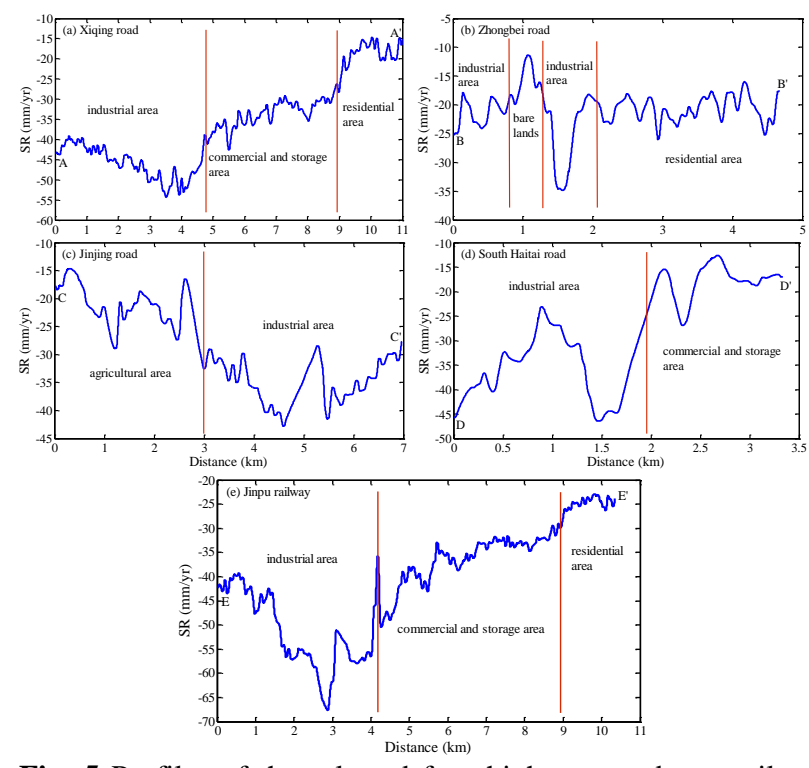

Fig. 5 Profiles of the selected four highways and one railway line

Table 3 Maximum, minimum and mean SRs (mm/yr) at the selected highways and railway line

\begin{tabular}{cccc}
\hline Name & Maximum & Minimum & Mean \\
& SR & SR & SR \\
\hline Xiqing road (AA') & -54.5 & -14.6 & -36.3 \\
Zhongbei road (BB') & -34.8 & -11.4 & -21.1 \\
Jinjing road (CC') & -43.1 & -14.6 & -28.8 \\
South Haitai road (DD') & -34.8 & -11.9 & -21.3 \\
Jinpu railway (EE') & -67.8 & -22.8 & -41.0 \\
\hline
\end{tabular}

Further inspections with Fig. 2 and Fig. 4 indicate that dense industrial parks and residential quarters are located along both sides of the selected highways and railway line. The LLUC along each highway and the railway line is annotated in Fig. 5. The subsidence troughs revealed by the profiles are mostly located near the industrial areas, while the sections with relatively lower SRs locates around residential areas, agricultural areas, and commercial and storage areas. Closer inspection of Fig. 2, Fig.4 and Fig. 5 (a) and (e) shows that the maximum SRs along Xiqing road and Jinpu railway are observed near the thermal power plant. As interpreted in section 4.1, groundwater pumping due to productive and domestic water needs in the residential and industrial regions is accountable for the subsidence in and around these areas. It can be inferred that the pumping has indeed affected the neighboring highways and railway line. Therefore, some measures should be taken to optimize the groundwater use planning and decrease the groundwater pumping. However, groundwater pumping is not the only factor affecting the studied transportation facilities. Another origin responsible for the remarkably uneven subsidence of the highways and railway line is the dynamic load from heavy vehicles such as trucks and trains. The external uneven forces from the dynamic loads can cause heterogeneous surface deformations to the highways and railway line, thus leading to the observable uneven subsidence.

\subsection{Subsidence Validation with Leveling Data}

For validation purpose, we used the in-situ leveling data to assess the accuracy and reliability of the SR measurements derived by TSX PSI. We compared the SR results derived by the TSX PSI with those derived by leveling, i.e., SR data obtained at the LPs (as marked in Fig. 2) by three epochs of precise leveling campaigns. Fig. 6 shows the comparison between two types of SRs at the LPs deployed along each of the selected highways. Statistical analysis indicates that the discrepancies between the two types of SRs at all the LPs range between -5.1 and $4.2 \mathrm{~mm} / \mathrm{yr}$, while those at the LPs on each highway range between -3.0 and $3.2 \mathrm{~mm} / \mathrm{yr},-3.2$ and $4.1 \mathrm{~mm} / \mathrm{yr}$, -5.1 and $2.7 \mathrm{~mm} / \mathrm{yr}$ and -2.4 and $4.2 \mathrm{~mm} / \mathrm{yr}$, respectively. The mean and standard deviation (STD) of the discrepancies at all LPs are 0.1 and $\pm 3.2 \mathrm{~mm} / \mathrm{yr}$, respectively. The results demonstrate that the high resolution TSX PSI is useful for monitoring subsidence related to the highways and railways with millimeter level accuracy.

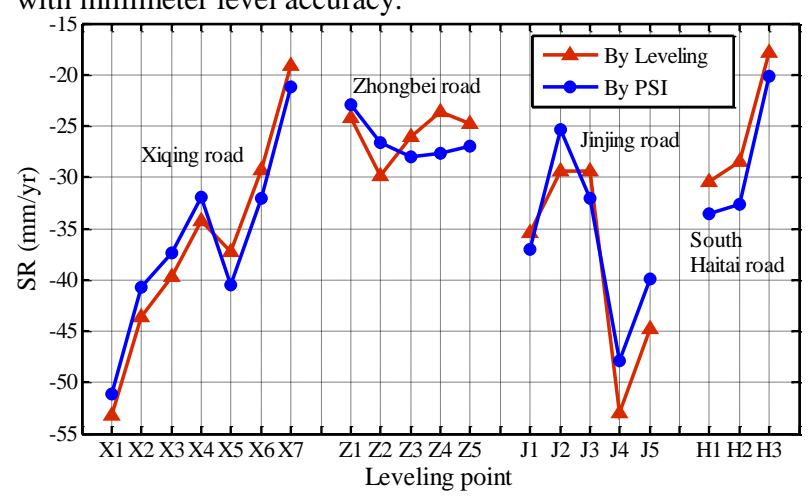

Fig. 6 Comparison between subsidence results derived from leveling and from the PSI solution at 20 LPs deployed along the selected highways

\section{CONCLUSIONS}

For better exploration of subsidence related to the TN, we propose to use high resolution TSX PSI approach to monitor the regional scale subsidence both along and around the TN. Xiqing district of southwest Tianjin (China) is selected as the study area where multiple highways and one railway line are located. For subsidence extraction, 15 TSX SAR images acquired between March, 2009 and June, 2010 are used for PSI analysis. The quality of subsidence measurements derived by the TSX PSI solution is assessed with the ground truth data obtained by precise leveling.

From the SR map, it is found that the study area is highly affected by uneven subsidence. The maximum, minimum and mean SRs are $-69,-1.3$ and $-33.7 \mathrm{~mm} / \mathrm{yr}$, respectively. Intersections with the optical images and our in-situ investigations demonstrate that the subsidence pattern is highly related to the LLUC. The subsidence troughs in the study area are located in and around the thermal power plant, industrial parks and residential quarters. The subsidence in these regions is found owing to aquifer compression caused by excessive groundwater extraction. The SR profile of each highway and the railway line shows the remarkably uneven subsidence along these transportation facilities. The peak SRs at the highways and railway line distribute near the thermal power plant, industrial parks, while the relatively smaller SRs are found near the residential quarters. The results indicate that groundwater pumping in these areas has affected the studied transportation facilities. Therefore, some measure should be taken to optimize the groundwater use planning and mitigate groundwater pumping. The validation with leveling data shows that the discrepancies between the two types of SRs at all the LPs are within $-5.1 \sim 4.2 \mathrm{~mm} / \mathrm{yr}$. The mean and STD of the discrepancies are 0.1 and $\pm 3.2 \mathrm{~mm} / \mathrm{yr}$, respectively. 
The results demonstrate that the PSI method based on high resolution $(2 \mathrm{~m})$ TSX SAR images is useful in assessing the subsidence related to the transportation networks. The subsidence measurements derived by the TSX PSI method can reach up to a millimeter level accuracy. It should be emphasized that the TSX PSI can provide us regional scale subsidence with very high spatial coverage rate. This is helpful in detecting the subsidence troughs which have high possibilities to cause damages to the highways and railways. Furthermore, the high resolution and regional scale characteristics of TSX PSI are advantageous in revealing mechanism and origins of the subsidence phenomena.

\section{ACKNOWLEDGEMENTS}

This work was jointly supported by the National Basic Research Program of China (973 Program) under Grant 2012CB719901, the National Natural Science Foundation of China under Grant 41074005, the R\&D Program of Railway Ministry under Grant 2008G031-5, the 2013 Doctoral Innovation Funds of Southwest Jiaotong University and the Fundamental Research Funds for the Central Universities under Grants (SWJTU11CX139, SWJTU10ZT02, SWJTU11ZT13). We thank Infoterra GmbH and USGS for providing TerraSAR-X SAR images and SRTM DEM, respectively.

\section{REFERENCES}

1. Rondinelli D, Berry M (2000) Multimodal transportation, logistics, and the environment: managing interactions in a global economy. European Management Journal 18(4): 398-410

2. Wu X, Hu SJ, Cui YP et al (2005) Study on the evaluation of harmonious development between railway transportation and economy. Journal of the China Railway Society 27(3): 20-25 (in Chinese)

3. Miller RD, Xia JH , Steeples DW (2009) Seismic reflection characteristics of naturally-induced subsidence affecting transportation. Journal of Earth Science 20(3): 496-512

4. Hu RL, Yue ZQ, Wang LC, Wang SJ (2004). Review on current status and challenging issues of land subsidence in China. Engineering Geology 76: 65-77

5. Massonnet D, Feigl KL (1998) Radar interferometry and its application to changes in the Earth's surface. Review of Geophysics 36(4): 441-500

6. Helmut R (2009) Advances in interferometric synthetic aperture radar (InSAR) in earth system science. Progress in Physical Geography 33(6): 769-791

7. Zebker HA, Villasenor J (1992) Decorrelation in interferometric radar echoes. IEEE Transactions on Geoscience and Remote Sensing 30(5): 950-959

8. Ding XL, Li ZW, Zhu JJ et al (2008) Atmospheric effects on InSAR measurements and their mitigation. Sensors 8: 5426-5448

9. Ferretti A, Prati C, Rocca F (2001) Permanent scatterers in SAR interferometry. IEEE Transactions on Geoscience and Remote Sensing 39(1): 8-20

10. Hooper A, Zebker H, Segall P et al (2004) A new method for measuring deformation on volcanoes and other natural terrains using InSAR persistent scatterers. Geophysical Research Letters 31, L23611

11. Mora O, Mallorqui JJ, Broquetas A (2003) Linear and nonlinear terrain deformation maps from a reduced set of interferometric SAR images IEEE Transactions on Geoscience and Remote Sensing 41(10): 2243-2253

12. Liu GX, Buckley SM, Ding XL et al (2009) Estimating spatiotemporal ground deformation with improved persistent-scatterer radar interferometry. IEEE Transactions on Geoscience and Remote Sensing 47(9): 3209-3219

13. Liu GX, Jia HG, Zhang $R$ et al (2011) Exploration of subsidence estimation by persistent scatterer InSAR on time series of high resolution TerraSAR-X images IEEE Journal of Selected Topics in Applied Earth Observations and Remote Sensing 4(1): 159-169

14. Wegmüller U, Walter D, Spreckels V et al (2010) Nonuniform ground motion monitoring with TerraSAR-X persistent scatterer interferometry," IEEE Transactions on Geoscience and Remote Sensing 48(2): 895-904

15. Enviro-Library (2009) Challenges and prospects of sustainable water management in Tianjin, 2008. Sustainable Groundwater Management in Asian Cities, 17 pp. http://enviroscope.iges.or.jp/modules/envirolib/upload/981 /attach/07_chapter3-4tianjin.pdf, [accessed 02 July, 2009] 